\title{
CHALLENGES AND OPPORTUNITIES IN HEALTHCARE VOLUNTEER MANAGEMENT: INSIGHTS FROM VOLUNTEER ADMINISTRATORS
}

\author{
Published in: \\ Hospital Topics, 91(2), 43-51
}

\author{
Sean E. Rogers \\ School of Management and Labor Relations \\ Rutgers, The State University of New Jersey
}

Carmen M. Rogers

College of Education and Health Professions

University of Arkansas

\section{Karen D. Boyd}

College of Business

Saint Ambrose University 


\begin{abstract}
In this article, volunteer administrators from 105 hospitals in five states in the northeast and Southern U.S. provided open-ended survey responses about what they perceived to be the most pressing challenges and opportunities facing healthcare volunteer management. Taken together, these 105 hospitals used a total of 39,008 volunteers and 5.3 million volunteer hours during a 12month period between 2010 and 2011. A qualitative content analysis of administrator responses suggests that primary challenges include volunteer recruitment and retention, administrative issues, and operational difficulties brought about by the current economic crisis. Key opportunities include more explicitly linking the volunteer function to hospital outcomes and community impact, expanding volunteer recruitment pools and roles and jobs, and developing organizational support for volunteers and making the volunteer management function more efficient and effective.
\end{abstract}


Healthcare Volunteer Management Challenges and Opportunities

\section{INTRODUCTION}

According to the U.S. Bureau of Labor Statistics, between September 2009 and September 2010, 5 million Americans volunteered in hospitals and healthcare organizations. This accounted for 8 percent of all U.S. volunteers during that period. Hospital volunteering is a longstanding tradition, with hospitals having an age-old practice of using a mixed workforce of paid and volunteer labor (Handy and Srinivasan 2004; Handy and Srinivasan 2005). While the historical role of hospital volunteers has been in auxiliaries responsible for gift shop operations and small-scale fundraising, more and more hospitals are currently relying on volunteers to provide increased professional and support services, governance, and fund-raising (Handy and Srinivasan 2004). With this increase in volunteer scope and utilization, many hospitals have turned to hiring professional administrators to manage volunteers efficiently (Handy and Srinivasan 2004). As Weil and Kimball $(2010,116)$ noted, "Virtually every hospital in America has a department dedicated to recruiting and managing volunteers."

Several studies have considered the recent trends, challenges, and opportunities for volunteers in the healthcare sector, including changing demographics from older to younger volunteers (Dow 1997), increasing volunteer preferences for well-defined work commitments that are shorter in duration (LaPerriere 1998), and more highly-skilled volunteers with clear personal and professional goals and expectations for assignments that are personally interesting and varied (Handy and Srinivasan 2004). While these and other challenges and opportunities are primarily derived from scholars' observation of environmental factors and focus on the experiences and expectations of volunteers, in this paper we provide a platform for the perspectives of the volunteer administration professionals hired to manage hospital volunteers and the volunteer function. This approach is a key contribution of the present paper, and sheds 
light on what leaders in the field actually see and are faced with on an everyday basis. Thus, it complements existing literature by providing a ground-level, practice-based administrative view of healthcare volunteer management which can serve as the basis for enhanced hospital management and research inquiry.

\section{DATA AND METHODS}

The data analyzed in this article were collected as part of a larger survey research project on hospital strategic orientation, volunteer resource management (VRM) practices, and volunteer and hospital performance outcomes. In August 2011, surveys with postage-paid return envelopes were mailed to the "Director of Volunteer Services" at 496 hospitals in five states in the northeast and Southern U.S. These 496 hospitals represented a complete listing of hospitals in those five states on the Medicare Hospital Compare website (www.hospitalcompare.hhs.gov), and were thus selected so that Hospital Consumer Assessment of Healthcare Providers and Systems (HCAHPS) survey data could be obtained for statistical analysis in the larger study. Hospitals in the northeast and the South were selected in order to capitalize on potential respondents' familiarity with two of the authors' institutional affiliations at the time of data collection, which are large public universities with high name recognition in their respective regions.

In October 2011, follow-up reminders were mailed. By December 31, 2011, the end of our survey collection period, 131 completed surveys had been returned, for a response rate of 26 percent. Of the 131 volunteer administrators who returned a completed survey, 105, or 21 percent of the original sample, provided write-in responses to the following survey question: "Regarding volunteer resource management, what do you see as the biggest challenges and opportunities for volunteer administrators in your position, and for volunteer management in 
general?"

Write-in responses were analyzed using a multi-stage, inductive analytic strategy. First, word clouds were created for all written challenges and opportunities. A word cloud is a "special visualization of text" in which words are depicted in a visual space, with more frequently used words showing more prominently in the graphic representation (McNaught and Lam 2010, 630). Ramsden and Bate (2008) noted that word clouds can be useful for researchers in quickly analyzing survey responses, and McNaught and Lam (2010, 631) demonstrated its potential for "studies that involve qualitative/thematic analyses of written or transcribed spoken text," particularly as "a tool for preliminary analysis...providing direction for detailed analysis in following stages." Both word clouds are shown in Figure 1.

\section{[Insert Figure 1 about here]}

The first author reviewed the word clouds, and then created preliminary categories of volunteer management challenges and opportunities. Then, the first and second authors coded the write-in data from all 105 respondents, sorting responses into the word cloud-generated categories, and making notes for further discussion and thematic clarification. From this process, the preliminary categories were refined. In most cases, multiple categories were condensed to create broader, more comprehensive idea-capturing categories. For example, the original "challenges" categories of staff, time, and pay issues were condensed into a single theme called administrative issues.

In other cases, single categories were expanded to account for important related ideas. For example, as a result of the original word cloud analysis, recruiting was a prominent challenge identified by volunteer administrators, whereas retention was mentioned much less often and is visually smaller in size. This led to recruiting, but not retention, being initially coded 
as an important challenge theme. However, the second, more detailed two-author analysis revealed that retention was just as salient a challenge for administrators as recruitment, and that retention was mentioned together with recruitment in most responses, although recruitment was more frequently identified specifically by name.

The final result of this iterative theme creation process was a six category coding scheme - three categories of challenges, and three categories of opportunities. The three challenges themes included: (1) recruitment and retention, (2) administrative issues, and (3) hospital operational difficulties brought about by the current economic crisis. The three opportunities themes included: (1) more explicitly linking the volunteer function to hospital outcomes and community impact, (2) expanding volunteer recruitment pools and roles and jobs, and (3) developing organizational support for volunteers, and making the volunteer management function more efficient and effective.

To further explore the appropriateness of these six categories as a coding scheme, a third independent rater was asked to code all write-in data according to the six themes, and a reliability analysis using the Kappa statistic was performed to compare the consistency between the independent ratings and the combined original ratings of the first and second author. The Kappa statistic is a more conservative approach to analyzing rater agreement than direct proportional agreement because it takes into account the fact that some degree of rater consistency will be purely random. Thus, “Cohen's [Kappa statistic] is a measure of the observed proportion of agreement that is greater than would be expected by chance" (Rust and Cooil 1994, 2).

For each of the six themes, percent agreement of rater judgments ranged from 97 and 100 percent, yielding Cohen's Kappa values of .49, .49, .49, .66, .66, and $1.00(\mathrm{p}<.001)$. Landis and 
Koch (1977) described Kappa values of between .41 and .60 as indicating a moderate strength of agreement, between .61 and .80 as substantial agreement, and between .81 and 1.00 as almost perfect agreement. For the three categories for which Kappa values did not reach a substantial level of agreement or higher (.60 or higher), the raters reviewed each of the differently-rated responses, clarified and discussed differences in judgments, and reached agreed-upon final categorizations. The six-category coding scheme was maintained.

\section{FINDINGS}

Of the 105 volunteer administrators that comprise our sample, 48 percent worked in hospitals in rural areas, 44 percent worked in hospitals in urban or metropolitan areas, and four percent worked in hospices, specialty clinics, or rehabilitation centers. The remaining four percent of respondents identified their facility as "Other." For the entire sample, the number of patient beds per hospital ranged from 15 to 864, with an average of 267 . An annual average of 372 volunteers provided 50,148 hours per year per hospital.

\section{Key Challenges}

Volunteer recruiting and retention was the most pressing challenge cited by volunteer administrators. This is not surprising, as empirical studies and popular press articles about how to attract and keep volunteers dominate the volunteerism literature. Regarding recruiting and retention, many respondents were concerned about the changing demographics of the volunteer workforce. As one noted, “The majority of [our] volunteers are retired and aging." Several others echoed this sentiment, adding that the retirees who they used to be able to rely upon are “working for pay much longer, perhaps into their 70's" and "just don't seem to be coming as much.” Middle aged, early career, and youth volunteers also posed challenges for many administrators. Some noted the general lack of time or interest in volunteering among this group, 
compared to previous generations. Others pointed specifically to the managerial challenges of high school, and particularly college, students who volunteer primarily to gain working experience or to fulfill diploma or degree requirements, rather than to genuinely help out. One administrator responded, "Few younger people are available. [They] only volunteer when school and/or college require it." Another commented that "Students...[are] looking for very short hours and time periods," and that "A challenge for me is to have high school students commit to [our hospital's] 50 hours requirement." A final important aspect of this challenge was the recruitment and retention of volunteers with high and specific skills. Administrators mentioned problems "finding the exact skills set" needed and "finding volunteers with higher skills and/or specific [skills]."

The second most cited challenge involved what we term administrative issues. This is an amalgamation of issues related to the volunteer administration function itself, the intersection between hospital administration and paid staff and volunteers, and considerations of time, pay, and status. Several respondents shared the sentiment of one administrator who remarked that "Facility executives never really understand the depth of [the] volunteer services department's responsibilities, functions, and level of productivity." Others added that despite wearing multiple hats, oftentimes the "DVS (director of volunteer services) is the lowest paid manager in the institution" and is "not considered a real manager," and that the "[volunteer management profession is not acknowledged as part of [hospital] leadership." In terms of time, administrators noted not having enough time to complete the wide range of tasks they are held responsible for. "Being a 1 person department," remarked one administrator, "I manage the volunteers, auxiliary, gift shop, and off-site thrift store. Getting everything done correctly in a time fashion [is] my biggest challenge." Related to time and workload burdens was the lack of resources, particularly 
the need for more paid staff to help with volunteer administration. One respondent noted the need to "expand paid staffing in order to do more effective [volunteer] recruitment and retention."

Finally, volunteer administrators expressed that their hospitals were currently working in difficult financial and operating environments caused, in part, by the larger national economic malaise, and that these difficulties were trickling down to all areas of their hospital, especially volunteering. For example, administrators noted that while high unemployment was in some areas creating larger pools of potential volunteers, many "people now volunteer with [the] agenda of receiving a paid position" and "are looking for work and...only want to volunteer to find a job," thus making it difficult for hospitals and volunteer administrators to make stable expectations of volunteer supply. Others noted that budget cuts and paid staff reductions in their own hospitals were leading departments to now look to volunteers to "fill in" duties that were once performed by employees.

\section{Key Opportunities}

Administrators viewed more explicitly linking volunteer efforts and the work of the volunteer function to hospital outcomes and community impact as the biggest opportunity for hospital volunteer administration. As one respondent noted, "In these days of pay for performance, volunteer management has an unprecedented chance to really be creative in providing programs and amenities via volunteers that touch the lives of both patients and visitors, and positively impact patient satisfaction scores." Another administrator added, "[Our hospital has] a big opportunity to increase patient satisfaction scores if the volunteer [function] could be used to [its] full potential." Several managers also recognized the potential to build bonds with local communities. "Volunteers are great PR people in the community," one commented. Another remarked that volunteers provide "great opportunities...to connect community members 
to their local hospital."

The second most mentioned opportunity was expanding volunteer recruitment pools and roles and jobs, and administrator responses directly tackled many of the aforementioned recruitment and retention challenges. "Flexible scheduling" and "continuous cross-training" were mentioned as ways in which older and working volunteers might be motivated to continue volunteering. Many also suggested using contemporary methods of recruitment and communication, including "webinars... and social networking” targeted toward specific populations (e.g., high school and college students, persons with disabilities, professionals with key skills, or the currently unemployed). Administrators also commented on the need to expand volunteer jobs so that they allow volunteers to utilize their existing skills or learn and develop new ones. Job rotation, or permitting volunteers to periodically work in several departments, rather than being locked into a single job, was also mentioned as one way in which hospitals can enhance the volunteer function. As one administrator noted, "Those volunteers that are now coming into our hospital bring many skills. There are continuous opportunities to develop new volunteer placements and activities.”

Finally, volunteer administrators highlighted the potential for developing organizational support for volunteers and making the volunteer management function more efficient and effective. Several echoed the sentiment of two administrators who identified "working closely with the administration and management team to increase our hospital's dedication to volunteers" and "involving senior management even more to support the work of the volunteers" as key growth areas. In addition, many administrators mentioned the potential for computer-based volunteer management software to increase volunteer management effectiveness. One commented, "I have just implemented a new volunteer management [software] program. This is 
a tremendous opportunity for growth."

\section{DISCUSSION AND RECOMMENDATIONS}

Our qualitative analysis of what volunteer administrators viewed as their most pressing challenges and promising opportunities reveals a wide range of issues that touch many aspects of the volunteer function in healthcare. Considering the six challenges and opportunities described above, several targeted recommendations are possible. However, rather than proffer multiple proposals aimed at addressing each of the issues discussed above individually, we instead present two overarching, actionable, results-focused recommendations which we believe subsume several narrower recommendations, and which we feel provide wide-reaching systematic solutions that can synergistically work to enhance healthcare volunteering outcomes. These include implementing strategic volunteer resource management, and developing a volunteer performance management system.

\section{Recommendation \#1: Implement Strategic Volunteer Resource Management}

When it comes to paid employees, most everyone is familiar with what is meant by human resource management (HRM). However, a less well-known and implemented concept is strategic HRM (SHRM). Wright and McMahan $(1992,298)$ define SHRM as "the pattern of planned human resource deployments and activities intended to enable an organization to achieve its goals." Simply put, SHRM is an applied field of management that blends the academic disciplines of strategy and HR, and emphasizes the strategic importance of effectively managing the human resources of organizations (Delery \& Doty 1996). SHRM is distinct from the more typical domain of HRM in that, whereas HRM is concerned with the application and efficacy of single HR practices, SHRM is concerned with the degree of alignment of HR practices with themselves (horizontal fit) and with organizational strategy (vertical fit). 
When a firm implements SHRM, the result is a well-oiled HRM system of complementary, high-performance-targeted HR practices that allows it to realize individual employee, team, and organizational objectives. Organizational implementations of SHRM have been linked to higher employee satisfaction, productivity, motivation, and commitment; lower employee turnover; and even organizational climate, sales growth, and stock price performance (Batt 2002; Chuang and Liao 2010; Delery 1998; Huselid 1995; Guthrie 2002; Lepak, Liao, Chung, and Harden 2006; Osterman 1994; Pil and MacDuffie 1996).

We propose that hospital executives and volunteer administrators would do well to work together to develop and implement a comprehensive workforce strategy for volunteers and the volunteer management function in their facilities. Doing so would help to: (1) ensure that the volunteer function is properly aligned with the hospital's larger organizational goals and objectives and is in a position to, when running well, add value and positively contribute to the hospital's bottom line; (2) clarify the role of volunteers and the volunteer administration function within the hospital's entire workforce strategy, thereby legitimizing equal support for all forms of work and workers within the organization; and (3) provide volunteer managers with practical, action-oriented guidelines and strategies for high-performance VRM.

Strategic VRM would directly address several of the challenges and opportunities administrators in our sample raised. Managers often cited that they did not have the time to effectively manage the volunteer function in their hospital, or that they lacked resources, or that the volunteer function lacked the full support of hospital staff and leaders. One possible reason for this might be that current organizational investments in volunteers and the volunteer function do not reflect the potential value they can contribute to key hospital outcomes, such as HCAHPS patient satisfaction ratings. If a clear and quantifiable line of sight is drawn between volunteer 
administration resources and capabilities, volunteer management practices, volunteer performance, and organizational performance, hospital executives might view the volunteer workforce as even more of a critical partner for hospital success, and as a high-value-added asset worth generously investing organizational resources into.

Similarly, volunteer administrators lamented about recruitment and retention problems, such as highly skilled volunteers who want specific jobs assignments, or younger volunteers averse to making long-term volunteering commitments. Under a strategic VRM system, changing and evolving volunteer demographics, particularly more complex and varied skills and abilities, would not be frustratingly viewed by administrators as a constraint that does not fit well with current volunteer management policies and procedures. Rather, such new and unplanned complexities would be welcomed as an opportunity to link new labor supply characteristics to hospital goals and objectives, and to multiply the potential bottom-line impact of the volunteer workforce on hospitals.

A comprehensive VRM strategy would provide hospitals and volunteer administrators an important and valuable tool that can help volunteers and the volunteer function contribute its full potential to patients and organizational outcomes.

\section{Recommendation \#2: Develop a Volunteer Performance Management System, or Include the Volunteer Function in Existing Performance Management Efforts}

Many public and nonprofit organizations, private corporations and small businesses, and governmental agencies rely on performance management (PM) systems to enhance operational efficiency and effectiveness and achieve organizational goals. This is especially true when it comes to managing human resources. In hospitals in particular, surveys like the HCAHPS are specifically designed as PM tools to help assess the quality of services, and the data obtained 
through these and other instruments are used to continually enhance organizational capabilities and target areas for personnel improvement. Despite the value that PM efforts yield hospitals and the larger human and social services sector, volunteers and the volunteer function are oftentimes overlooked by and not included in them.

Our second recommendation is that hospitals and volunteer administrators work together to develop a PM system that can accurately and completely assess the contributions and effectiveness of volunteers and the volunteer function. This might involve creating a standalone, volunteer-focused PM system, or formally including the volunteer workforce and volunteer administration into an existing PM program. A formal, deliberate volunteer PM system would not only help hospital reach desired end goals, but would also provide systematic assistance in the practical management of the volunteer function. Hatry (2010, S210) noted that in addition to bottom-line organizational goals, PM “can be used for a number of managerial purposes, such as day-to-day resource allocation, motivating employees, motivating contractors, developing and justifying capital and operating budgets, [and] communicating to the public." Thus, volunteer PM would specifically provide a tool to hospital administrators to capture the full potential of volunteer efforts, and of the volunteer workforce to hospital outcomes.

We ground our recommendation of a volunteer PM system by adopting commonlyaccepted conceptualizations of PM in organization administration scholarship. Particularly, we view PM as primarily including two elements: (1) performance measurement - the measurement of outputs and outcomes, and (2) performance information use - managerial and organizational willingness to use performance data in decision-making (Hatry 2010). While several specific typologies of PM exist (e.g., management by objectives, total quality management, balanced scorecard), they all revolve around the idea of collecting and utilizing performance data for 
organization management.

The first prong of a volunteer PM system is performance measurement. Given the formalization of volunteerism in hospitals, performance measurement likely exists to some degree. Many volunteer departments annually report metrics such as hours volunteered, the number of volunteers, and funds raised by volunteers. While these are a good start, a volunteer PM system that is intended to both improve the capabilities of volunteers and highlight the contribution and potential of the volunteer function to bottom-line hospital outcomes needs to be designed so that a majority of meaningful metrics can be captured and analyzed in a timely manner. What constitutes a "meaningful" performance metric will depend on a hospital's overall mission and goals and its strategy and purpose for the volunteer workforce, and each administrator needs to determine what data would be useful for their organization. Examples might include gift shop receipts or customer satisfaction ratings, pints of blood raised through mobile blood drives, or the number of pet visits conducted by volunteers each year. Increasingly and as noted above, volunteer administrators are turning to electronic volunteer management systems to track such metrics, and we believe this is a move in the right direction toward comprehensive volunteer PM.

Quickly and accurately capturing data represents only one piece of the PM puzzle. Utilizing these data to improve operations is the other, arguably more important, piece. Noted Harvard performance management scholar Robert Behn (2002) once quipped that possible reasons PM, despite being a great idea, had yet to take over the world is because it is difficult for managers to do, it creates fear and uncertainty for worker and managers, and it requires multiple organizational actors (including administrators and employees) to think differently about their roles and responsibilities. Indeed, de Lancer Julnes and Holzer (2001) found that PM data 
collection, and even the formal adoption of a PM program, was much more prevalent that actual managerial use of performance information in organizational decision-making and operations.

Within a volunteer PM system of the sort we recommend, volunteer administrators would use the data they collect to drive their daily managerial activities, and to guide their mid-and long-range volunteer workforce planning. For example, volunteer hours worked and turnover totals would be compared to previous year trends, as well as the totals of comparable hospitals, to determine whether the potential for improvement or to explore untapped volunteer labor markets exists. Similarly, fundraising activities could be analyzed to determine whether efficiency (e.g., in terms of dollars per volunteer or dollar per hour worked) might be enhanced.

As with an effective VRM strategy, implementation of a data-driven, strategicallyaligned volunteer PM system would help to make the volunteer function an even more highly valued hospital stakeholder, clearly delineating the line-of-sight between volunteer performance and bottom-line hospital outcomes.

\section{LIMITATIONS AND FUTURE RESEARCH}

Although our data provide important insight into the issues facing hospital volunteer directors, and allow us to formulate policy and practice recommendations, certain limitations of the study must be noted. Of primary note, our sample consisted only of hospitals located in five northeastern and Southern U.S. states, rather than a nationally or globally-representative selection of healthcare organizations. While volunteer administrators in our sample reported a wide variety of current challenges and opportunities, we cannot be sure that their perspectives cover all of the issues other administrators in other parts of the U.S. and the world may be encountering. This is especially true given wide variations in population diversity and density, services provided, budgetary capabilities and constraints, and the like. As a result, the 
generalizability of our findings and the recommendations that flow from them must be approached with caution.

A second limitation is the timing of the data collection. We queried hospital volunteer administrator in the summer and fall of 2011, a time of great change and economic uncertainty in the U.S. It is reasonable to assume that much of what was going on outside of hospitals was influencing operations within hospitals. This is perhaps most evidenced by the fact that one of the most-reported challenges was operational difficulty brought about by macroeconomic and budgetary pressures. Presumably, hospital volunteer management challenges and opportunities will not remain the same forever. In considering the present and future state of the volunteer function in healthcare, it is important to remember that this study represents perspectives from a snapshot in time.

One final limitation is the applicability of our findings to volunteers and volunteer management as a whole. The volunteer function within hospitals has a long and storied history and tradition, as discussed at the beginning of this paper, and does not necessarily reflect all organizations which utilize volunteer labor. Practitioners and researchers should take into account contextual differences across organizational and sector-specific characteristics when reading, interpreting, and applying our results and recommendations.

Limitations notwithstanding, the findings of this study provide a way forward for future researchers. One near-term goal would be to replicate this effort with a larger and more nationally and globally-representative sample. This would help to flesh out a more comprehensive understanding of the challenges and opportunities facing healthcare volunteer administrators. Another future suggestion is to explore the ways in which hospitals are effectively exploiting their opportunities and managing their challenges. Perhaps there are model 
organizations out there that are reaping the benefits of successful implementation of strategic volunteer resource management, or a volunteer performance management system, or some other approach. A case study or ethnography, for example, might be able to uncover the mechanisms by which effective volunteer management can add value to healthcare organizations and their stakeholders.

\section{CONCLUSION}

In this article we set out to highlight the voices of those whose job it is to manage volunteers and the volunteer function within hospitals. Our analysis revealed that while hospital volunteer administrators see several opportunity areas for enhancement, they face a myriad of challenges in their day-to-day operations, including issues of volunteer recruitment and retention, administrative issues, and operational constraints resulting from their hospitals larger external environment. We provided two broad-based recommendations - strategic volunteer resource management and a volunteer performance management system - that we believe can help volunteer administrators effectively manage their daily challenges and exploit those opportunities they see on the horizon. In the end, we believe the future is bright for healthcare volunteerism, and agree with one respondent who remarked, “Aren’t all our challenges opportunities?" 
Healthcare Volunteer Management Challenges and Opportunities

\section{References}

Batt, R. 2002. Managing customer services: Human resource practices, quit rates, and sales growth. Academy of Management Journal 45: 587-97.

Behn, R. D. 2002. The psychological barriers to performance management: Or why isn't everyone jumping on the performance-management bandwagon? Public Performance \& Management Review 26: 5-25.

Bureau of Labor Statistics. 2011. Volunteering in the United States, 2010. Accessed December 21, 2011. http://www.bls.gov/news.release/volun.nr0.htm.

Chuang, C. H., and H. Liao. 2010. Strategic human resource management in service context: Taking care of business by taking care of employees and customers. Personnel Psychology 63: 153-96.

de Lancer J. P., and M. Holzer. 2001. Promoting the utilization of performance measures in public organizations: An empirical study of the factors affecting adoption and implementation. Public Administration Review 61: 693-708.

Delery, J. E. 1998. Issues of fit in strategic human resource management: Implications for research. Human Resource Management Review 8: 289-310.

Delery, J. E., and D. H. Doty. 1996. Modes of theorizing in strategic human resource management: Tests of universalistic, contingency, and configurational performance predictions. Academy of Management Journal 39: 802-35.

Dow, W. 1997. The voluntary sector: Trends, challenges, and opportunities for the new Millennium. Vancouver, Canada: Volunteer Vancouver.

Handy, F., and N. Srinivasan. 2004. Valuing volunteers: An economic evaluation of the net benefits of hospital volunteers. Nonprofit and Voluntary Sector Quarterly 33 (28): 28-54.

Handy, F., and N. Srinivasan. 2005. The demand for volunteer labor: A study of hospital volunteers. Nonprofit and Voluntary Sector Quarterly 34: 491-509.

Hatry, H. P. 2010. Looking into the crystal ball: Performance management over the next decade. Public Administration Review 70: 208-11.

Huselid, M. A. 1995. The impact of human resource management practices on turnover, productivity, and corporate financial performance. The Academy of Management Journal 38 (3): 635-72.

Guthrie, J. P. 2002. High involvement work practices, turnover, and productivity: Evidence from New Zealand. Academy of Management Journal 44: 180-90. 
Landis, J. R., and G. G. Koch. 1977. The measurement of observer agreement for categorical data. Biometrics 33 (1): 159-74.

LaPerriere, B. 1998. Volunteerism in the Canadian Health Sector. Ottawa, Canada: Volunteer Canada.

Lepak D. P., H. Liao, Y. Chung, and E. H. Harden. 2006. A conceptual review of human resource management systems in strategic human resource management research. In Research in Personnel and Human Resources Management, edited by J. Martocchio, 217-71. Oxford, UK: Elsevier.

Osterman, P. 1994. How common is workplace transformation and who adopts it? Industrial and Labor Relations Review 47: 173-88.

Pil, F.K., and J. P. MacDuffie. 1996. The adoption of high-involvement work practices. Industrial Relations 35: 423-55.

Rust, R. T., and B. Cooil. 1994. Reliability measures for qualitative data: Theory and implications. Journal of Marketing Research 31: 1-14.

Weil, P. A., and P. A. Kimball. 2010. The volunteer activities of healthcare executives. Journal of Healthcare Management 55 (2): 115-31.

Wright, P. M., and G. C. McMahan. 1992. Theoretical perspectives for strategic human resource management. Journal of Management 18: 295-320. 
Figure 1: Word Cloud Analysis of Hospital Volunteer Administrators' Perceived Challenges and Opportunities. Respondent $\mathrm{N}=105$.

\section{CHALLENGES}

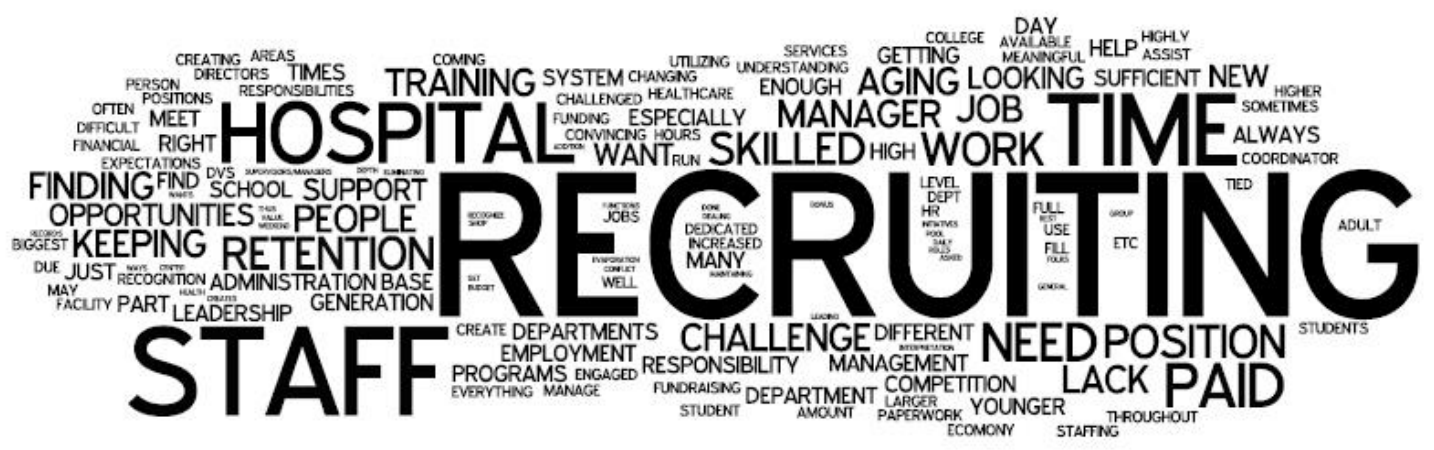

\section{$\underline{\text { OPPORTUNITIES }}$}

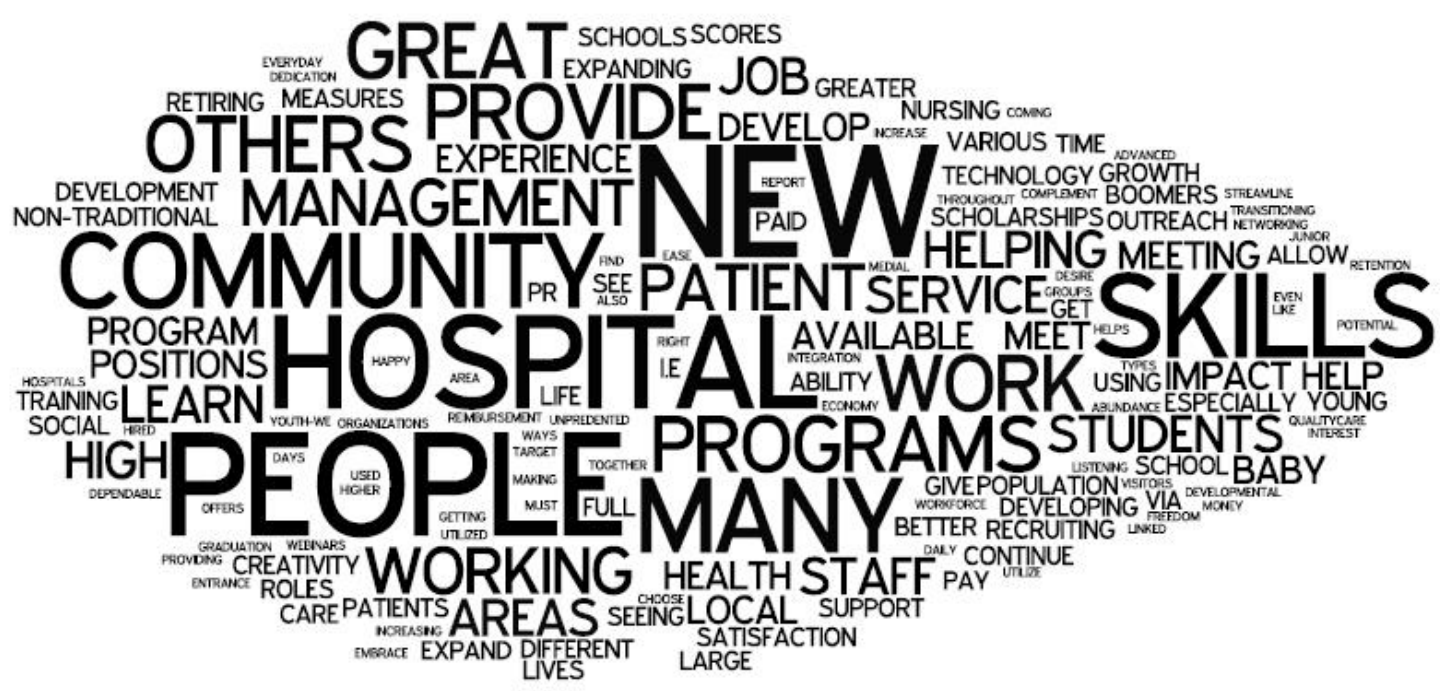

